\title{
Practice does not Make Perfect in Learning Grammar
}

\author{
Si-Jia XUE \\ The International College of Xiamen University, Xiamen, 361102, Peoples R China \\ xuesijia@126.com
}

Keywords: Grammar learning, Second language acquisition, Factors

\begin{abstract}
Grammar learning and teaching has consistently been regarded as a crucial part in the domain of second language acquisition. However, notions upon effective approach to learning grammar have never reached agreement. The cultivation of a learner's communicative competence is the ultimate goal of acquiring a language, therefore grammar learning should also be communicative and the traditional conception that grammar acquisition is just rote-learning through practicing grammatical rules ought to be questioned as well. Nevertheless, communicative grammar does not exclude grammatical rules but is instructed through such appropriate means as task-based teaching. As the medium of delivering explicit grammar knowledge, teaching material is important in learning grammar and formulaic materials are of great significance during the process. It has been identified that grammar acquisition follows certain natural orders, thus the teaching of grammar should also adhere to such developmental sequences in learners as grammar learning is an implicit cognitive process. Learner's motivation is another factor affecting grammar learning and motivational strategies can be employed in order to achieve the optimum learning outcomes.
\end{abstract}

\section{Introduction}

Grammar can be simply defined as the way a language controls and connects words (or bits of words) in order to form longer semantic units (Ur, 1988:4). It is apparent that grammatical rules are crucial for the mastery of a language and the role of grammar in language teaching is always esteemed important. However, the exclusive role of grammar teaching was challenged in the early 1970 s by the notion of 'communicative competence'. To be a competent user of a language, the learner should not only master the essential grammatical rules, but also how the rules can be applied in communication (Richards \& Renandya, 2002:145). While the agreement upon the importance of grammar teaching is reached by the majority of scholars, new issue on how grammar can be taught and learnt more effectively has arisen since then.

Practicing grammatical rules is consistently favoured by many teachers as well as learners. Nevertheless, when it is featured as rote-learning irrelative communicative language application, practice is of little benefit to grammar acquisition, and in that case, 'practice does not make perfect' (Lightbown, 2000:443). Grammar learning is a systematic cognitive process and explicit learning of grammatical rules dose not equal implicit acquisition of learners'. Thus, unlike learning how to use a musical instrument, only practicing cannot lead to perfect grammar acquisition. Ellis also doubts the efficacy of practice in grammar learning because the acquisition of grammar involves many other parameters as well (2002:170). According to Lightbown, only when practice is interpreted as opportunities for meaningful language use, can it be beneficial, however, apart from communicative practice, effective grammar learning may also be affected by factors such as developmental sequences, teaching material and even learners' motivation (ibid: 444). Therefore, the present paper will discuss how these parameters may contribute to successful grammar learning and what can be done in order to improve the learners' performance in acquiring grammar, justifying Lightbown's assertion that practice does not make perfect in learning grammar.

\section{Communicative Grammar}

The aim of language learning is the cultivation of the learners' communicative competence. 'Proficiency' is frequently used to indicate the same purpose and proficiency testing has been 
recognized prevailingly as a means of measuring the learners' communicative competence (Garrett, 1986:133). However, it is common that students at college or university level, having the ground of grammar in the language after many years of school acquisition, are disappointingly proficient in applying the language; and the phenomenon is described as 'grammar fatigue' (Leech \& Svartvik, 2002:3).

The problem is prevalent in grammar learning and is generally accepted by both the teachers and students. Students are constantly unable to apply the learned grammar items appropriately to real communication even though these grammar items have been instructed, demonstrated and practiced repeatedly. What is worse is that the achievement of communicative competence may be hindered by the attention paid to grammatical forms because the learners' attention is diverted from the expression of meaning to grammatical rules; and the former is vital to the language use whereas the latter is not (Garrett, 1986:133).

The fundamental reason for the failure of effective application of grammar in communication is the traditional conceptions of grammar. It was commonly believed that grammar is a set of arbitrary conventions governing a language system and is only associated with forms. Consequently the preferred method of learning grammar is to practice these rules repeatedly. However, the examples described above prove that learners after rote-learning in grammar are far from being proficient and the function of mechanical practice outside meaningful language use in grammar acquisition is limited.

Therefore, another means of learning grammar should be taken into account. By this grammatical rules are systematically connected with meanings, uses and situations, and the learners' competence can be enhanced through the application of these rules in communication (Leech \& Svartvik, 2002:3). The core of such approach is the notion that grammar is a way of expressing meanings by means of grammatical forms, which illustrate the ultimate stage of an interaction process in which messages are communicated in a situation. Thus grammatical competence involves not only the knowledge of rules, but also the ability to apply meaningful grammar in real situations, which is also considered as part of the communicative competence (Newby, 1998:154).

Nevertheless, to be communicative in grammar learning does not mean the total ignorance of forms and explicit instruction is still crucial to grammar acquisition (Ellis, 2002:17). On the contrary, explicit grammar can be converted into implicit grammar through communicative taskbased component (ibid: 31). Notwithstanding the limitation such as little relationship between the tasks and the world outside the classroom, task-based teaching style is beneficial to the learners in grammar learning due to its characteristics (Cook, 2008:260).

Task-based teaching can be employed to accomplish communicative grammar. This teaching style requires the learners to acquire a language by using it in communicative way thus it not only involves learning but also processing during the learning process; tasks and activities on a grammatical point are organized in communicative style and communicative strategies are employed; it emphasizes meaning and requests the learners to use the language to achieve a particular goal (ibid: 258). In a learning process as such, the practice on grammar is referred as 'opportunities for meaningful language use and for thoughtful, effortful practice of difficult linguistic features', hence it is crucial to the acquisition (Lightbown, 2000:443). However, the implementation of such teaching style needs to be supplemented with teaching materials of a communicative nature. In other words, teaching material is another factor that may affect grammar learning and will be discussed in the following section.

\section{Teaching Materials}

Materials reveal the writers' perspectives of language and learning, and teachers and learners adapt the materials according to their own situations and the extent to which the materials match their beliefs and expectations (Crawford, 2002:84). The writers of materials for grammar learning often take these aspects into account, such as the age and level of the learners, the methodology employed, the contexts involved, the nature of the grammatical points and the difficulties the learners may encounter when dealing with these grammatical items (Stranks, 2003:330). The 
teachers and learners then select the most effective materials according to their own needs and appropriate teaching materials may function as helpful scaffold making the learning process more efficient.

Materials should be authentic. This is also emphasized by many scholars (Tomlinson, 1998; Gilmore, 2007; Crawford, 2002). According to Gilmore (2007:98), authentic materials should be 'a stretch of real language, produced by a real speaker or writer for a real audience and designed to convey a real message of some sort'. Crawford also asserts that the more realistic the materials, the more easily it can meet the needs of different proficiency levels involved in a class (2002:85). Exposure to authentic input in the materials can be provided through the activities suggested as well as the instructions for the activities; and the materials should be abundant and diverse in style, mode, medium, purpose and features; and the learners should be able to interact with the input rather than just receive it passively. However, the input must be understandable to facilitate acquisition (Tomlinson, 1998:13).

Materials ought to raise the learners' consciousness. Consciousness-raising is constantly valued by researchers in grammar learning. Based on examples, Ellis suggests that discovery-type grammar tasks should be included in grammar practice materials to raise learners' awareness about the target grammatical points (Ellis, 2002:176). Similarly, Schmidt believes the importance of noticing and proposes that, under equal circumstance, the more frequent a form, the more likely it is to be noticed and then be acquired by the learners (Skehan, 1998:48). Crucial in this process is that a gap between a particular feature of their interlanguage and the equivalent feature in the target language can be noticed by the learners and such noticing of the gap can function as an 'acquisition facilitator' (Seliger, 1979 in Tomlinson, 1998:14).

Materials should provide the learners with the opportunities to use the grammatical points communicatively and not depend considerably on controlled practice. It is universally agreed by most researchers that the goal of language teaching is to cultivate learners able to communicate competently and that the learners should be provided opportunities to apply the language for communicative purpose rather than just to practice it in contexts controlled by the teacher and materials (ibid: 14). As Sharwood-Smith says (1981), learners are given opportunities to pick up language from the input through communicative interaction, as well as opportunities to offer information for input (ibid: 15). While such controlled practice activities as dialogues are still popular and are regarded as useful means of learning grammar by both the teachers and learners, researchers claim that 'controlled practice seems to have little long term effect on the accuracy with which new structures are performed' (Ellis, 1990:192) and 'has little effect on fluency' as well (Ellis and Rathbone, 1987 in Tomlinson, 1998:21).

Materials should also take into account the diversity of learners. Learners are different from one another in various ways. Different learners may prefer different learning styles, for example, learners prefer learning from formal instruction may benefit much more from explicit grammar teaching than those who prefer experiential learning (ibid: 17). Learners tend to have different backgrounds, experiences and attitudes towards the linguistic knowledge they are exposed to as well. Although it is impossible to cater for all the variables, the teaching materials should be diversified to provide, for example, options of diverse types of text, activities, to meet the needs of different learners (ibid: 18). After all, learning a language is principally an individual process in which learners incorporate new knowledge into their existing language system. Hence both the teachers and materials should be aware of and cater for these individual differences to guarantee the learning results (Crawford, 2002:87).

Formulaic materials appear to be beneficial for learners in learning grammar. The significant role of formulaic sequences in language acquisition, both for children and adults, has been recognized by many researchers (Mitchell and Martin, 1997; Wray, 1999; Wood, 2002). According to Wray (1999:214), formulaic sequences can be defined as 'a sequence, continuous or discontinuous, of words or other meaning elements, which is, or appears to be, prefabricated: that is, stored and retrieved whole from memory at the time of use, rather than being subject to generation or analysis by the language grammar'; and studies have already begun to focus on the positive function 
formulaic sequences perform in language acquisition in recent years. Although research on the relationship between formulaic sequences and grammar acquisition is limited, some scholars believe that connected words in formulaic sequences may provide natural access to grammatical knowledge (Wray, 2000:473).

However, for guided language learning, both the instruction and materials should match the natural language acquisition processes because there are natural sequences of acquisition among learners in some areas of language learning such as grammar acquisition; and only when the instruction and materials coincide with learners' readiness can effective acquisition be achieved.

\section{Developmental Sequences}

Notwithstanding the lack of explanation, the natural learning orders in second language acquisition (SLA), particularly in SLA grammar learning, have been discovered by many researchers (White, 1989; Andersen, 1991; Macaro, 2003; Cook, 2008). It is claimed that certain grammatical items are acquired in a particular order and cannot be acquired easily when the orders are shifted, and these developmental sequences are similar regardless of the learners' first language (Macaro, 2003:25).

Take learning English grammar for example, learners from different backgrounds share a common sequence of development, which can be generally divided into six stages: 1 . the learners start with the production of one single word or formulas. 2. next the typical subject verb object (SVO) word order is acquired, and negatives are put in the front of the sentence. 3. adverbials are put at the beginning of the sentence and wh-words are used at this stage without inversion. 4 . The separation of preposition from its phrase is discovered by the learners at stage four and they start to use '-ing' ending. 5. question-word questions and '-s' ending of verbs are acquired at this stage. 6. finally the learners acquire the order of subordinate clauses (Cook, 2008:29).

Moreover, second language learners of English also tend to demonstrate the similar order of difficulty in learning grammar. For example, plural 's' is the least difficult for them to master whereas passive ' $s$ ' is the most difficult; and they frequently make the same types of mistake whatever the first language they speak (ibid: 27). In spite of the different interpretations of these orders, it is commonly agreed that the sequences relate to the learners' growing ability to process language in their mind and they are 'inevitable progression of learners through definite stages of acquisition', and if the teaching sequences of grammar do not coincide these stages undue demands on learners may be created (ibid: 33 ).

Therefore, grammar teaching should be conducted accordingly at different stages of the learners. In other words, the learning process should follow the developmental sequences as closely as possible; otherwise, the learning efficiency will be affected however the practice is performed. Although it still remains controversial, the teachability hypothesis is significant in guiding the teaching of grammar. According to Pienemann (1984:201), 'an L2 structure can be learnt from instruction only if the learner's interlanguage is close to the point when this structure is acquired in the natural setting'. Thus the word order of questions should never be expected at the early stages when the learners can only acquire the fundamental order of SVO (Cook, 2008: 31).

Based on the hypothesis of teachability, the most beneficial type of teaching should be one that triggers the next developmental stage of the learners. Formal instruction cannot affect the acquisition sequences and the learners can conquer the processing restraints arising at each stage by producing prerequisites for the following stage; if the teaching is far beyond the present stage of the learners, failure to move to a higher stage will be generated (Pienemann, 1984:203). The proposal has been supported by other researchers such as Mackey and Philp (1998), who focused on other aspect of English grammar acquisition and discovered that the 'ready' group of participants was far more likely to get access to an advanced stage than the 'unready' group in acquiring the structure investigated (Macaro, 2003:27). 


\section{Learners' Motivation}

Motivation is another factor that may affect the language acquisition. The conception of motivation in SLA is defined by Gardner as 'the extent to which the individual works or strives to learn the language because of a desire to do so and the satisfaction experienced in this activity' (1985:10). According to his socio-educational model, there are two types of motivation, the integrative and the instrumental: the former relates to learners' desire to learn the language in order to interact and incorporate with the language community (ibid: 54); and the latter refers to the learners' need to acquire the language for getting a job, passing an examination or achieving some other practical goals (ibid: 11). Thus different learners may learn the same language or grammatical items because of different types of motivation and the teachers should be aware of this and make it favourable to language acquisition. Although different researchers have diverse definitions and categories of SLA motivation, the significant role motivation plays in SLA is commonly agreed.

Various components constitute the L2 motivation. According to Williams and Burden's framework (1997), motivation can be composed of internal and external factors; the former may include elements such as the intrinsic interest and perceived value of activity, the learners' attitude towards the language, other affective states, and the developmental age and stage; while the latter may involve such components as the learning environment, the broader context and significant others (Dornyei, 2001:20). Although L2 motivation is a complex and multi-dimensional construct, it is apt to be influenced by these factors and it changes over time; and the change of motivation may affect the L2 acquisition as well. Only when these factors are realized and well shaped can they contribute to effective learning.

In order to preserve and promote learners' motivation in acquiring the language, some motivational strategies can be employed. According to Dornyei (ibid: 28), motivational strategies refer to 'those motivational influences that are consciously exerted to achieve some systematic and enduring positive effect'. Based on this definition, four key units are suggested in a motivational teaching practice: creating the basic motivational conditions, generating initial motivation, maintaining and protecting motivation, and encouraging positive retrospective self-evaluation (ibid: 29).

Several steps can be taken to accomplish these units. First, both a pleasant and helpful teaching environment and a cohesive learner group with proper group standards should be built in the classroom to create the basic motivational conditions, and the teachers should behave appropriately to set good examples for the students. Then generate initial motivation, which involves these requirements such as creating realistic beliefs and orienting the goal directions for the learners, promoting the learners' values and attitudes towards the language, and making the teaching materials relevant for the learners. In order to maintain and protect learners' motivation, teachers should make the learning enjoyable and inspiring, demonstrate tasks in a motivating manner, set specific goals for the learners, and improve the learners' self-motivating strategies. Finally, teachers ought to provide motivational feedback, offer motivating rewards and grades to learners, and increase learners' satisfaction to encourage positive retrospective self-evaluation for them (ibid: 29).

All these pieces of advice illustrate that as different learners may hold different types of motivation in learning the same language and various factors may contribute to these diversities, teachers should become familiar with the specificity of their students and apply appropriate approach to maintain, promote and encourage the learners' motivation, which is significant in acquiring the language and may influence the final learning results, therefore, should be paid particular attention to.

\section{Conclusion}

The current paper starts with the justification of Lightbown's 'practice does not make perfect' in learning grammar, explaining that apart from practice, successful grammar acquisition may be 
contributed to by other factors such as teaching styles, teaching materials, learners' developmental sequences and their motivation for learning.

To enhance the learners' linguistic competence and cultivate users who are able to apply the language proficiently in real communicative way ought to be the aim of language teaching, and grammar teaching should also be communicative. Thus mechanical practice irrelevant to meaningful context is far from satisfaction and the effect of rote-learning is very limited. Despite the limitation, task-based teaching can be suggested as an ideal teaching style in achieving communicative grammar teaching because meaningful language use is emphasized in this practice. However, a communicative teaching style should be complemented with teaching materials of a communicative nature. Reflecting learners' needs and expectations as well as writers' beliefs and perspectives of language learning, teaching material is another important factor influencing effective grammar acquisition. Authenticity is the basic requirement for teaching materials. Besides, they ought to raise consciousness, provide communicative opportunities and cater to the individual differences for the learners. Although further confirmation is needed, formulaic materials may be beneficial for learners in learning grammar. Learning sequence is influential in grammar acquisition and is not affected by formal instruction. Hence teaching should follow the natural process of grammar acquisition and facilitate the learners' transition from one stage to next. Motivation is also important in effective acquisition of grammar because it is the inner drive of learners' behaviors. As many factors may affect the learners' motivation the teachers should be aware of these elements as well as the specificity of the learners, and make effort to maintain, promote and encourage learning motivation for them.

To sum up, the exclusive role of practice in learning grammar should be challenged because grammar acquisition is a multi-dimensional construct and it also involves many other parameters. Only when these factors are well balanced and complement practice in appropriate approach can practice make perfect in grammar acquisition.

\section{References:}

[1] Ur, P. Grammar Practice Activities: A practical guide for teachers. Cambridge: Cambridge University Press, 1988

[2] Richards, J. C. \& Renandya, W. A. Methodology in Language Teaching: An anthology of current practice. Cambridge: Cambridge University Press, 2002

[3] Lightbown, P. M. Anniversary Article: Classroom SLA Research and Second Language Teaching. Applied Linguistics, 21 (4), (2000) 431-462

[4] Ellis, R. Methodological Opinions in Grammar Teaching Materials. In Hinkel, E. \& Fotos, S. (eds.) New Perspectives on Grammar Teaching in Second Language Classroom,(2002) pp.156-179

[5] Garrett, N. The Problem With Grammar: What Kind Can the Language Learner Use?. The Modern Language Journal, 70(2),(1986) 133-148

[6] Leech, G. \& Svartvik, J. A Communicative Grammar of English. London: Pearson Education, 2002

[7] Newby, D. Theory and Practice in Communicative Grammar: A Guide for Teachers, 1998. In R. de Beaugrande, M. Grosman \& B. Seidlhofer, (eds.), Language Policy and Language Education in Emerging Nations, Series: Advances in Discourse Processes, 63,151-164.

[8] Ellis, R. The Place of Grammar Instruction in the Second/Foreign Language Curriculum. In Hinkel, E. \& Fotos, S. (eds.) New Perspectives on Grammar Teaching in Second Language Classroom,(2002) pp.17-34

[9] Cook, V. Second Language Learning and Language Teaching. London: Hodder Education, 2008 
[10] Crawford, J. The Role of Materials in the Language Classroom: Finding the Balance. In In Richards, J. C. \& Renandya, W. A. (eds). Methodology in Language Teaching: An anthology of current practice, (2002) pp.80-91

[11] Stranks, J. Materials for the Teaching of Grammar. In Tomlinson, B. (ed.) Developing Materials for Language Teaching, (2003) pp.329-339

[12] Tomlinson, B. Materials Developing in Language Teaching. Cambridge: Cambridge University Press, 1998

[13] Gilmore, A. Authentic materials and authenticity in foreign language learning. Language Teaching, 40, (2007) 97-118

[14] Ellis, R. Grammar Teaching-Practice or Consciousness-Raising?. In Richards, J. C. \& Renandya, W. A. (eds). Methodology in Language Teaching: An anthology of current practice, (2002) pp.167-174

[15] Skehan, P. A Cognitive Approach to Language Learning. Oxford: Oxford University Press, 1998

[16]Ellis, R. Instructed Second Language Acquisition. Oxford: Basil Blackwell, 1990

[17] Mitchell, R. \& Martin, C. Rote Learning, Creativity and 'Understanding' in Classroom Foreign Language Teaching. Language Teaching Research, 1,(1997) 1-27

[18] Wray, A. Formulaic language in learners and native speakers. Language Teaching, 32, (1999) 213-231

[19] Wood, D. Formulaic Language in Acquisition and Production: Implications for Teaching. TESL Canada Journal, 20 (1), (2002) 1-15

[20] Wray, A. Formulaic Sequences in Second Language Teaching: Principle and Practice. Applied Linguistics, 21 (4), (2000) 463-489

[21] White, L. Universal Grammar and Second Language Acquisition. Amsterdam: John Benjamins Publishing, 1989

[22] Andersen, R. W. Developmental Sequences: the emergence of aspect marking in second language acquisition. In Huebner, T. \& Ferguson, C. A. (eds.) Crosscurrents in Second Language Acquisition and Linguistic Theories, (1991) pp.305-324

[23] Macaro, E. Teaching and Learning a Second Language: a guide to recent research and its application. New York: Continuum, 2003

[24] Pienemann, M. Psychological Constraints on the Teachability of Languages. Studies in Second Language Acquisition, 6 (2), (1984) 186-214

[25] Gardner, R. C. Social Psychology and Second Language Learning: The Role of Attitudes and Motivation. London: Edward Arnold, 1985

[26] Dornyei, Z. Motivational Strategies in the Language Classroom. Cambridge: Cambridge University Press, 2001 